\title{
Henri Meschonnic entre langue et poésie, sous la direction de Marcella Leopizzi
}

Sara Arena

\section{Q OpenEdition}

1 Journals

\section{Edizione digitale}

URL: http://journals.openedition.org/studifrancesi/2284

DOI: 10.4000/studifrancesi.2284

ISSN: 2421-5856

\section{Editore}

Rosenberg \& Sellier

\section{Edizione cartacea}

Data di pubblicazione: 1 aprile 2014

Paginazione: 186

ISSN: 0039-2944

\section{Notizia bibliografica digitale}

Sara Arena, « Henri Meschonnic entre langue et poésie, sous la direction de Marcella Leopizzi », Studi Francesi [Online], 172 (LVIII | I) | 2014, online dal 01 avril 2014, consultato il 18 septembre 2020. URL : http://journals.openedition.org/studifrancesi/2284 ; DOI : https://doi.org/10.4000/studifrancesi.2284

Questo documento è stato generato automaticamente il 18 settembre 2020.

\section{(c) (i) $\odot$}

Studi Francesi è distribuita con Licenza Creative Commons Attribuzione - Non commerciale - Non opere derivate 4.0 Internazionale. 


\title{
Henri Meschonnic entre langue et poésie, sous la direction de Marcella Leopizzi
}

\author{
Sara Arena
}

\section{NOTIZIA}

Henri Meschonnic entre langue et poésie, sous la direction de Marcella LEOPIZZI, «Studi di letteratura francese», XXXV-XXXVI, 2010-2011, pp. 207.

1 Come emerge dai due testi introduttivi alla silloge di interventi, riuniti in questo numero di «Studi di letteratura francese» quale ideale celebrazione dell'ottantesimo compleanno di Henri Meschonnic, scomparso nel 2009 (Giovanni Dotoli, Le Flambeau d'un message, pp. 11-14; Marcella LEOPIZZI, La Voix d'Henri Meschonnic: vivre-sentir poème, pp. 15-23), l'asse prescelto per la pubblicazione non si pone l'obiettivo di una presentazione esaustiva dell'opera di Meschonnic, ma di un'indagine unitaria nell'approccio, sul modello della produzione dell'autore.

Riflessione sulla lingua, riflessione sulla poesia, scrittura poetica, pratica e teoria della traduzione, sono in effetti in Meschonnic aspetti di un'unica e ininterrotta attività di indagine che si confonde interamente con la vita stessa del poeta e studioso: «Toute ma vie est dans mes poèmes, mes poèmes sont le langage de ma vie» (Vivre poème, Liancourt, Dumerchez, 2006, p. 7). Il fortissimo legame tra l'opera e la vita torna del resto in diversi dei contributi del volume, tra cui, in particolare, quello di Pascal MAILLARD (Henri Meschonnic, la vie pour le sens, pp. 171-177).

Il volume contiene così, oltre agli studi critici, anche alcune interessanti testimonianze, tra cui quelle della moglie Régine BLAIG (Tiens c'est pour toi, pp. 33-36; Construction d'un livre, pp. 37-38), che rivela, grazie anche a un inserto iconografico, la particolare tecnica di composizione dei libri adottata da Meschonnic, metodo che ricorda, nella 
suddivisione della materia in fiches tra loro artigianalmente collegate, l'efficace immagine di un «[o]rdinateur avant l'heure» (p. 37).

4 I ricordi personali di Jean-Claude CHEVALIER (Premiers pas avec Henri Meschonnic, premiers voyages, pp. 101-104) e il tributo di Claude RÉGY (Henri Meschonnic et ma révolution professionnelle, pp. 115-116) ricostruiscono attorno alla figura di Meschonnic il senso di una parabola umana, di un'epoca di scambi e di un lascito vivo nel panorama culturale francese. Il medesimo clima di entusiasmo intellettuale traspare dalla riflessione di Bernard Nö̈L (Pour Henri Meschonnic, pp. 111-114), che ripercorre la sua scoperta degli spazi bianchi nelle poesie di Meschonnic come «liaisons rythmiques», «foyer nerveux de l'échange et de la circulation du sens», e nei due documenti legati alla presenza di Meschonnic a Santo Domingo, in occasione della presentazione di Crise du signe nel 2000: il testo del discorso tenuto dallo stesso MEschonNic (Présentation de "Crise du signe", pp. 39-53), e la trascrizione di un'importante intervista all'autore condotta da Diógenes CÉSPEDES, (Entretien avec Henri Meschonnic, pp. 137-146).

5 Gli studi propriamente detti comprendono sia riflessioni trasversali all'intera opera, come il corposo studio di Giovanni DотоLI, Poétique du poème (pp. 65-90), che indaga nozioni fondamentali come quella di "poésie», «poème», «rythme», «voix», «vie», «sujet», sia affondi su singole raccolte, come avviene nello studio di L'Obscur travaille condotto da Marcella LEOPIZZI (Mouvement et lumière dans "L'Obscur travaille", pp. 91-100).

6 La medesima raccolta è indagata, insieme a De monde en monde e con riferimenti a saggi dell'autore, nello studio di Fabio sсотто che prende in esame in particolare la questione della soggettività, in Meschonnic spesso «metamorfica e plurale» (p. 118) (Le "Je" traversé. Sur quelques livres récents d'Henri Meschonnic, pp. 117-126). Il testo Modernité, modernité, del 1988, è invece al centro dello studio di Jacques ANCET (Pour le présent, pp. 59-64), che si interroga sul significato del termine «modernità» nella riflessione dell'autore.

7 Joëlle ZASK («Embabeler», pp. 147-154) mostra, attraverso il riferimento al mito della Torre di Babele, come Meschonnic abbia sistematicamente decostruito l'ideale di una perfetta aderenza e univocità tra segno, pensiero e cosa. La complessità come modalità di pensiero è del resto un'asse centrale della riflessione dell'autore, come appare nello studio di Gérard DESSONS, La Simplicité du complexe (pp. 155-158), che prende in particolare le mosse dalla lettura di Langage histoire une même théorie. Alla complessità è strettamente legato il tema dell'«altro», che Serge MARTIN, approfondisce comparando la visione della relazione in Meschonnic con quella di Paul Ricœur (Henri Meschonnic, la voix, la théorie, la relation. Courte fable du "entre", pp. 105-110).

8 A ulteriore testimonianza dell'attenzione di Meschonnic per la lingua nel suo rapporto inscindibile con l'etica e la politica, Jean-Louis chIss ripercorre gli articoli incentrati sull'impiego del termine Shoah (Henri Meschonnic. De l'attention au langage et de ses implications, pp. 159-162). Altri interventi si concentrano infine su un aspetto non minore dell'attività di Meschonnic, quello di traduttore, in particolare della Bibbia (David BANON, Une traduction décapante, pp. 127-136), e teorico della traduzione (JeanPatrice CoURToIs, Brèves remarques sur le problème de l'“ordre des mots" en traduction, pp. 163-170). È ancora la traduzione, e in particolare l'apparato di note del traduttore, a offrire un ponte di collegamento - attraverso la passione per il commento terminologico - tra Meschonnic e il celebre lessicografo Alain ReY (Pour Henri Meschonnic, un "exercice d'Amitié", pp. 55-58). 